\title{
DFT studies on the electronic structures of 4-methoxybenzonitrile dye for Dye-Sensitized Solar Cell
}

\author{
A. Prakasam ${ }^{1, *}$, D. Sakthi ${ }^{1}$, P. M. Anbarasan ${ }^{2}$ \\ ${ }^{1}$ Department of Physics, Periyar University, Salem - 636 011, Tamil Nadu, India \\ Phone: +91-0427-2345766,2345520, Fax No: +91-0427-2345565,2345124 \\ ${ }^{2}$ Centre for Nanoscience \& Nanotechnology, Periyar University, Salem - 636011 , \\ Tamil Nadu, India \\ *E-mail address: physicsprakasam@gmail.com
}

\begin{abstract}
The geometries, electronic structures, polarizabilities and hyperpolarizabilities of organic dye sensitizer 4-methoxybenzonitrile was studied based on ab initio HF and Density Functional Theory (DFT) using the hybrid functional B3LYP. Ultraviolet-visible (UV-Vis) spectrum was investigated by Time Dependent DFT (TDDFT). Features of the electronic absorption spectrum in the visible and near-UV regions were assigned based on TDDFT calculations. The absorption bands are assigned to $\pi \rightarrow \pi^{*}$ transitions. Calculated results suggest that the three excited states with the lowest excited energies in 4-methoxybenzonitrile is due to photoinduced electron transfer processes. The interfacial electron transfer between semiconductor $\mathrm{TiO}_{2}$ electrode and dye sensitizer 4-methoxybenzonitrile, is due to an electron injection process from excited dye to the semiconductor's conduction band. The role of nitro group in 4-methoxybenzonitrile in geometries, electronic structures, and spectral properties were analyzed.
\end{abstract}

Keywords: Dye sensitizer; Density functional theory; Electronic structure; Absorption spectrum

\section{INTRODUCTION}

Because of the depletion of fossil fuels, growing demand of energy, global warming and other environmental problems, the development of environmental friendly renewable energy technologies is an urgent task for our human being [1]. Among all the renewable energy technologies, the nanocrystalline dye-sensitized solar cell (DSSC) system, a kind of photovoltaic device that presented by O'Regan and Gratzel in 1991, has attracted a lot of attention because of the potential application for low-cost solar electricity [2-5]. The main parts of DSSC are mesoporous oxide semiconductor layers that composed of nanoparticles and monolayer of dye sensitizers that attached to the surface of the semiconductor nano-films [3]. The dye sensitizers play an important role in DSSC that have a significant influence on the photoelectric conversion and transport performance of electrode [6-9]. Up to now, two kinds of dye sensitizers, which are generally known as metal-organic complexes and metalfree organic dyes, were studied extensively. In metal-organic complexes, especially the noble metal ruthenium polypyridyl complexes, including N3 and black dye etc. that were presented by Gratzel et al., have proved to be the best dye sensitizers with overall energy conversion efficiency greater than $10 \%$ under air mass (AM) 1.5 irradiation [10-12]. 
However, the limited metal $\mathrm{Ru}$ will become a bottleneck of application if the DSSC is widely used in our daily living [13]. On the other hand, metal-free organic dyes as sensitizers for DSSC, including cyanines, hemicyanines, triphenylmethanes, perylenes, coumarins, porphyrins, squaraines, indoline, and azulene- based dyes etc., have also been developed because of their high molar absorption coefficient, relatively simple synthesis procedure, various structures and lower cost [14-16]. In contrast to the numerous experimental studies of dye sensitizers, the theoretical investigations are relatively limited. Only several groups focused on the electronic structures and absorption properties of dye sensitizers [17-26], and $\mathrm{Ru}$-complexes and organic dyes coupled $\mathrm{TiO} 2$ nanocrystalline [27-30], as well as the electron transfer dynamics of the interface between dyes and nanocrystalline [31-35]. Until now, it remains a severe challenge for both experiment and theory to elucidate the fundamental properties of the ultrafast electron injection [30], and to approach the satisfied efficiency of DSSC.

Further developments in dye design will play a crucial part in the ongoing optimization of DSSC [36], and it depends on the quantitative knowledge of dye sensitizer. So the theoretical investigations of the physical properties of dye sensitizers are very important in order to disclose the relationship among the performance, structures and the properties, it is also helpful to design and synthesis novel dye sensitizers with higher performance. Recently a rapid progress of organic dyes has been witnessed reaching close to $10.0 \%$ efficiencies in combination with a volatile acetonitrile-based electrolyte [37]. Nitrile is an important class of high performance dyes, which are easily processable, and display good mechanical properties, outstanding thermal and thermal-oxidative stability. Nitrile dyes were used for aerospace, marine, and electronic packaging applications by thermal treatment of nitrile derivatives at elevated temperatures (generally high up to $350^{\circ} \mathrm{C}$ ) for an extended period of time. In this paper the performance of 4-methoxybenzonitrile metal free dye that can be used in DSSC is analyzed.

\section{COMPUTATIONAL METHODS}

The computations of the geometries, electronic structures, polarizabilities and hyperpolarizabilities, as well as electronic absorption spectrum for dye sensitizer 4methoxybenzonitrile was done using ab initio HF and DFT with Gaussian03 package [38].

The DFT was treated according to Becke's three parameter gradient-corrected exchange potential and the Lee-Yang-Parr gradient-corrected correlation potential (B3LYP) [39-41], and all calculations were performed without any symmetry constraints by using polarized split-valence 6-311G(d,p) basis sets. The electronic absorption spectrum requires calculation of the allowed excitations and oscillator strengths.

These calculations were done using TDDFT with the same basis sets and exchangecorrelation functional in vacuum and solution, and the non-equilibrium version of the polarizable continuum model (PCM) $[42,43]$ was adopted for calculating the solvent effects. 


\section{RESULTS AND DISCUSSION}

\section{1. The geometric structure}

The optimized geometry of the 4-methoxybenzonitrile is shown in Fig. 1, and the bond lengths, bond angles and dihedral angles are listed in Table 1. Since the crystal structure of the exact title compound is not available till now, the optimized structure can be only be compared with other similar systems for which the crystal structures have been solved. From the theoretical values we can find that most of the optimized bond lengths, bond angles and dihedral angles. The optimized bond lengths of C1-C2 and C3-C4 is 1.4398 and $1.4304 \AA$ respectively at B3LYP/6-311G (d,p) and also well matched with $\mathrm{HF} / 6-311 \mathrm{G}(\mathrm{d}, \mathrm{p})$.

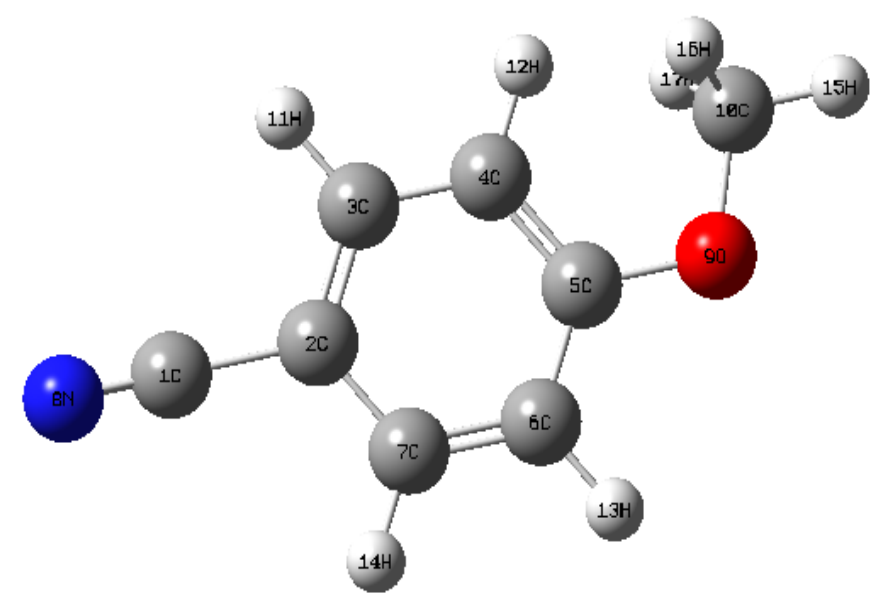

Fig. 1. Optimized geometrical structure of dye 4-methoxybenzonitrile.

Table 1. Bond lengths (in $\AA$ ), bond angles (in degree) and dihedral angles (in degree) of the dye 4-methoxybenzonitrile.

\begin{tabular}{|c|c|c|}
\hline Parameters & B3LYP/6-11++G(d,p) & HF /6-311++G(d,p) \\
\hline Bond length $(\AA)$ & & \\
\hline C1-C2 & 1.4274 & 1.4372 \\
\hline C1-N8 & 1.156 & 1.1313 \\
\hline C2-C3 & 1.3878 & 1.3716 \\
\hline C2-C7 & 1.4138 & 1.4051 \\
\hline C3-C4 & 1.396 & 1.3924 \\
\hline C3-H13 & 1.0808 & 1.0711 \\
\hline C4-C5 & 1.4236 & 1.4081 \\
\hline
\end{tabular}




\begin{tabular}{|c|c|c|}
\hline C4-N9 & 1.4598 & 1.4515 \\
\hline $\mathrm{C} 5-\mathrm{C} 6$ & 1.4204 & 1.4169 \\
\hline C5-N 12 & 1.3507 & 1.3427 \\
\hline $\mathrm{C} 6-\mathrm{C} 7$ & 1.3722 & 1.3605 \\
\hline C6-H14 & 1.0843 & 1.0746 \\
\hline $\mathrm{C} 7-\mathrm{H} 15$ & 1.0831 & 1.0746 \\
\hline N9-O10 & 1.2225 & 1.1852 \\
\hline N9-011 & 1.2386 & 1.1962 \\
\hline N12-H16 & 1.0091 & 0.9907 \\
\hline N12-H17 & 1.0058 & 0.9909 \\
\hline \multicolumn{3}{|l|}{ Bond Angle $\left(^{\circ}\right)$} \\
\hline $\mathrm{C} 1-\mathrm{C} 2-\mathrm{C} 3$ & 120.82 & 120.7568 \\
\hline $\mathrm{C} 1-\mathrm{C} 2-\mathrm{C} 7$ & 120.4361 & 120.4535 \\
\hline $\mathrm{C} 3-\mathrm{C} 2-\mathrm{C} 7$ & 118.7439 & 118.7897 \\
\hline $\mathrm{C} 2-\mathrm{C} 3-\mathrm{C} 4$ & 120.7341 & 120.6989 \\
\hline C2-C3-H13 & 121.0512 & 120.7302 \\
\hline C4-C3-H13 & 118.2147 & 118.5709 \\
\hline $\mathrm{C} 3-\mathrm{C} 4-\mathrm{C} 5$ & 121.4831 & 121.597 \\
\hline $\mathrm{C} 3-\mathrm{C} 4-\mathrm{N} 9$ & 116.6409 & 116.4489 \\
\hline $\mathrm{C} 5-\mathrm{C} 4-\mathrm{N} 9$ & 121.876 & 121.9542 \\
\hline $\mathrm{C}_{4}-\mathrm{C}_{5}-\mathrm{C}_{6}$ & 116.2433 & 116.1311 \\
\hline $\mathrm{C}_{4}-\mathrm{C}_{5}-\mathrm{N}_{12}$ & 124.4558 & 125.5603 \\
\hline $\mathrm{C}_{6}-\mathrm{C}_{5}-\mathrm{N}_{12}$ & 119.3018 & 118.3086 \\
\hline $\mathrm{C}_{5}-\mathrm{C}_{6}-\mathrm{C}_{7}$ & 122.1019 & 121.9626 \\
\hline $\mathrm{C}_{5}-\mathrm{C}_{6}-\mathrm{H}_{14}$ & 118.1319 & 118.1667 \\
\hline $\mathrm{C}_{7}-\mathrm{C}_{6}-\mathrm{H}_{14}$ & 119.7661 & 119.8707 \\
\hline $\mathrm{C}_{2}-\mathrm{C}_{7}-\mathrm{C}_{6}$ & 120.6946 & 120.8207 \\
\hline $\mathrm{C}_{2}-\mathrm{C}_{7}-\mathrm{H}_{15}$ & 119.43997 & 119.5326 \\
\hline $\mathrm{C}_{6}-\mathrm{C}_{7}-\mathrm{H}_{15}$ & 119.8657 & 119.6467 \\
\hline $\mathrm{C}_{4}-\mathrm{N}_{9}-\mathrm{O}_{10}$ & 118.5609 & 118.1504 \\
\hline
\end{tabular}




\begin{tabular}{|c|c|c|}
\hline $\mathrm{C}_{4}-\mathrm{N}_{9}-\mathrm{OS}_{11}$ & 118.2267 & 118.2267 \\
\hline $\mathrm{O}_{10}-\mathrm{N}_{9}-\mathrm{O}_{11}$ & 123.2124 & 123.6229 \\
\hline $\mathrm{C}_{5}-\mathrm{N}_{12}-\mathrm{H}_{16}$ & 119.5025 & 121.0429 \\
\hline $\mathrm{C}_{5}-\mathrm{N}_{12}-\mathrm{H}_{17}$ & 119.7927 & 119.2551 \\
\hline $\mathrm{H}_{16}-\mathrm{N}_{12}-\mathrm{H}_{17}$ & 120.7047 & 119.7014 \\
\hline $\mathrm{C}_{3}-\mathrm{C}_{4}-\mathrm{C}_{5}-\mathrm{C}_{6}$ & 0.041 & -0.011 \\
\hline $\mathrm{C}_{3}-\mathrm{C}_{4}-\mathrm{C}_{5}-\mathrm{N}_{12}$ & 180.0351 & 179.9939 \\
\hline $\mathrm{N}_{9}-\mathrm{C}_{4}-\mathrm{C}_{5}-\mathrm{C}_{6}$ & -179.9728 & 179.9681 \\
\hline $\mathrm{N}_{9}-\mathrm{C}_{4}-\mathrm{C}_{5}-\mathrm{N}_{12}$ & 0.0212 & -0.027 \\
\hline $\mathrm{C}_{3}-\mathrm{C}_{4}-\mathrm{N}_{9}-\mathrm{O}_{10}$ & -0.0408 & -0.0708 \\
\hline $\mathrm{C}_{3}-\mathrm{C}_{4}-\mathrm{N}_{9}-\mathrm{O}_{11}$ & 179.9811 & 179.9295 \\
\hline $\mathrm{C}_{5}-\mathrm{C}_{4}-\mathrm{N}_{9}-\mathrm{O}_{10}$ & 179.9724 & 179.9491 \\
\hline $\mathrm{C}_{5}-\mathrm{C}_{4}-\mathrm{N}_{9}-\mathrm{O}_{11}$ & -0.0057 & -0.0506 \\
\hline $\mathrm{C}_{4}-\mathrm{C}_{5}-\mathrm{C}_{6}-\mathrm{C}_{7}$ & -0.0348 & 0.0148 \\
\hline $\mathrm{C}_{4}-\mathrm{C}_{5}-\mathrm{C}_{6}-\mathrm{H}_{14}$ & 179.9702 & 180.0093 \\
\hline $\mathrm{N}_{12}-\mathrm{C}_{5}-\mathrm{C}_{6}-\mathrm{C}_{7}$ & -180.0291 & -179.9898 \\
\hline $\mathrm{N}_{12}-\mathrm{C}_{5}-\mathrm{C}_{6}-\mathrm{H}_{14}$ & -0.0241 & 0.0048 \\
\hline $\mathrm{C}_{4}-\mathrm{C}_{5}-\mathrm{N}_{12}-\mathrm{H}_{16}$ & -0.0316 & 0.1259 \\
\hline $\mathrm{C}_{4}-\mathrm{C}_{5}-\mathrm{N}_{12}-\mathrm{H}_{17}$ & 180.0762 & 179.8398 \\
\hline $\mathrm{C}_{6}-\mathrm{C}_{5}-\mathrm{N}_{12}-\mathrm{H}_{16}$ & -180.0377 & -179.8691 \\
\hline $\mathrm{C}_{6}-\mathrm{C}_{5}-\mathrm{N}_{12}-\mathrm{H}_{17}$ & 0.0701 & -0.1552 \\
\hline $\mathrm{C}_{5}-\mathrm{C}_{6}-\mathrm{C}_{7}-\mathrm{C}_{2}$ & 0.0082 & -0.0066 \\
\hline $\mathrm{C}_{5}-\mathrm{C}_{6}-\mathrm{C}_{7}-\mathrm{H}_{15}$ & -179.9925 & -180.0059 \\
\hline $\mathrm{H}_{14}-\mathrm{C}_{6}-\mathrm{C}_{7}-\mathrm{C}_{2}$ & 180.0031 & -180.001 \\
\hline $\mathrm{H}_{14}-\mathrm{C}_{6}-\mathrm{C}_{7}-\mathrm{H}_{15}$ & -0.0024 & -0.00031 \\
\hline
\end{tabular}

\section{2. Electronic structures and charges}

Natural Bond Orbital (NBO) analysis was performed in order to analyze the charge populations of the dye 4-methoxybenzonitrile. Charge distributions in $\mathrm{C}, \mathrm{N}$ and $\mathrm{H}$ atoms were observed because of the different electro-negativity, the electrons transferred from $\mathrm{C}$ atoms to 
$\mathrm{C}, \mathrm{N}$ atoms, $\mathrm{C}$ atoms to $\mathrm{H}$. The natural charges of different groups are the sum of every atomic natural charge in the group. These data indicate that the cyanine and amide groups are acceptors, while the acetic groups are donors, and the charges were transferred through chemical bonds. The frontier molecular orbitals (MO) energies and corresponding density of state of the dye 4-methoxybenzonitrile is shown in Fig. 2. The HOMO-LUMO gap of the dye 4-methoxybenzonitrile in vacuum is $4.37 \mathrm{eV}$.

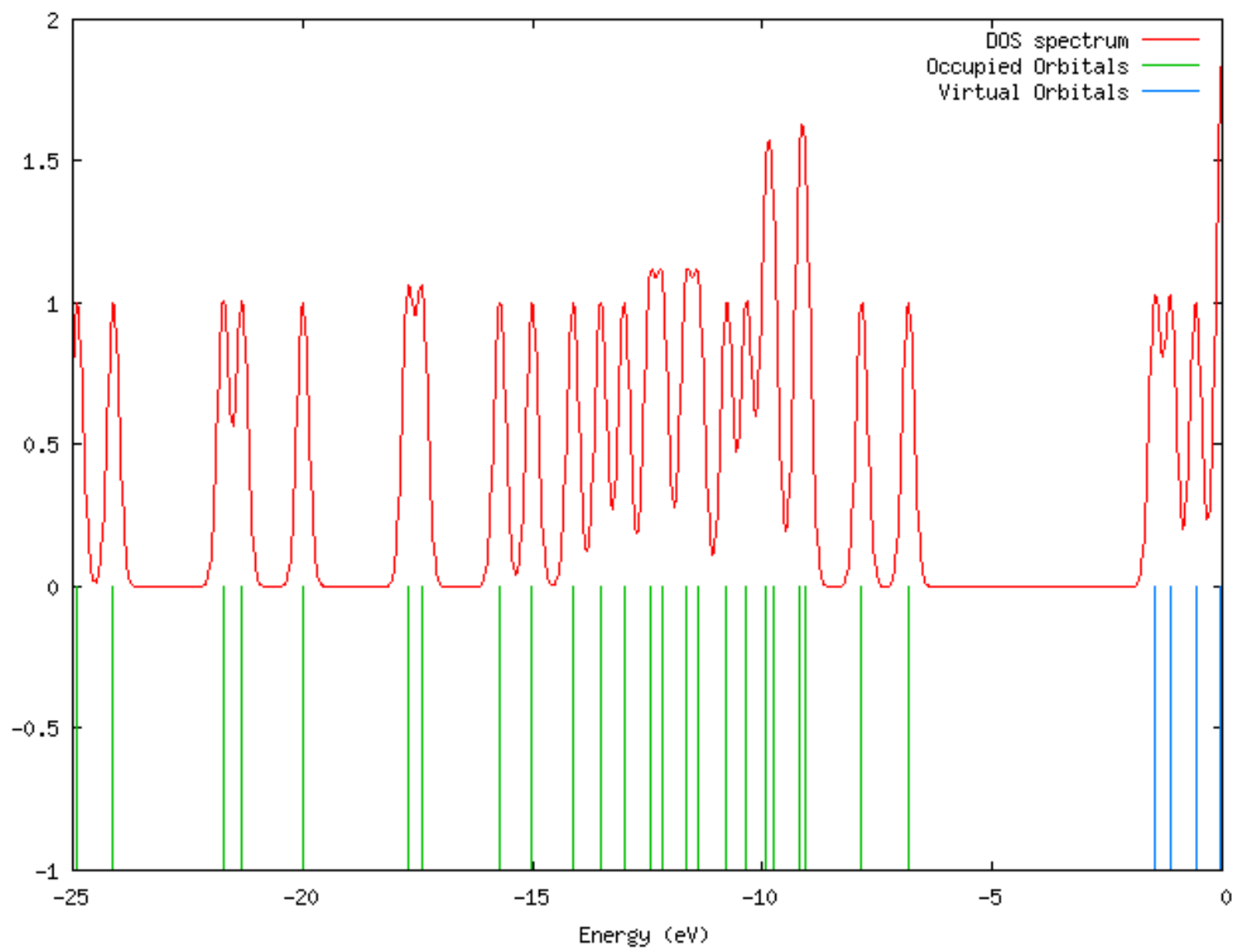

Fig. 2. The frontier molecular orbital energies and corresponding density of state (DOS) spectrum of the dye 4-methoxybenzonitrile.

While the calculated HOMO and LUMO energies of the bare $\mathrm{Ti}_{38} \mathrm{O}_{76}$ cluster as a model for nanocrystalline are -6.55 and $-2.77 \mathrm{eV}$, respectively, resulting in a HOMO-LUMO gap of $3.78 \mathrm{eV}$, the lowest transition is reduced to $3.20 \mathrm{eV}$ according to TDDFT, and this value is slightly smaller than typical band gap of $\mathrm{TiO}_{2}$ nanoparticles with nm size [44]. Furthermore, the HOMO, LUMO and HOMO-LUMO gap of $\left(\mathrm{TiO}_{2}\right)_{60}$ cluster is $-7.52,-2.97$, and $4.55 \mathrm{eV}$ (B3LYP/VDZ), respectively [45]. Taking into account of the cluster size effects and the calculated HOMO, LUMO, HOMO-LUMO gap of the dye 4-methoxybenzonitrile, $\mathrm{Ti}_{38} \mathrm{O}_{76}$ and $\left(\mathrm{TiO}_{2}\right)_{60}$ clusters, we can find that the HOMO energies of these dyes fall within the $\mathrm{TiO}_{2}$ gap.

The above data also reveal the interfacial electron transfer between semiconductor $\mathrm{TiO}_{2}$ electrode and the dye sensitizer 4-methoxybenzonitrile is electron injection processes from 
excited dye to the semiconductor conduction band. This is a kind of typical interfacial electron transfer reaction [46].

\section{3. Polarizability and hyperpolarizability}

Polarizabilities and hyperpolarizabilities characterize the response of a system in an applied electric field [47]. They determine not only the strength of molecular interactions (long-range intermolecular induction, dispersion forces, etc.) as well as the cross sections of different scattering and collision processes, but also the nonlinear optical properties (NLO) of the system $[48,49]$. It has been found that the dye sensitizer hemicyanine system, which has high NLO property, usually possesses high photoelectric conversion performance [50]. In order to investigate the relationships among photocurrent generation, molecular structures and NLO, the polarizabilities and hyperpolarizabilities of 4-methoxybenzonitrile was calculated.

The polarizabilities and hyperpolarizabilities could be computed via finite field (FF) method, sum-over state (SOS) method based on TD-DFT, and coupled-perturbed HF (CPHF) method. However, the use of FF, SOS, and CPHF methods with large sized basis sets for 4methoxybenzonitrile is too expensive. Here, the polarizability and the first hyperpolarizabilities are computed as a numerical derivative of the dipole moment using B3LYP/6-31G(d,p). The definitions $[48,49]$ for the isotropic polarizability is

$$
\alpha=\frac{1}{3}\left(\alpha_{X X}+\alpha_{Y Y}+\alpha_{Z Z}\right)
$$

The polarizability anisotropy invariant is

$$
\Delta \alpha=\left[\frac{\left(\alpha_{X X}-\alpha_{Y Y}\right)^{2}+\left(\alpha_{Y Y}-\alpha_{Z Z}\right)^{2}+\left(\alpha_{Z Z}-\alpha_{X X}\right)^{2}}{2}\right]^{\frac{1}{2}}
$$

and the average hyperpolarizability is

$$
\beta_{\square}-\frac{1}{\jmath}\left(\beta_{i i Z}+\beta_{i Z i}+\beta_{Z i i}\right)
$$

Where, $\alpha_{X X}, \alpha_{Y Y}$, and $\alpha_{Z Z}$ are tensor components of polarizability; $\beta_{i i Z}, \beta_{i Z i}$, and $\beta_{Z i i}$ (i from $\mathrm{X}$ to $\mathrm{Z}$ ) are tensor components of hyperpolarizability.

Tables 2 and 3 list the values of the polarizabilities and hyperpolarizabilities of the dye 4-methoxybenzonitrile. In addition to the individual tensor components of the polarizabilties and the first hyperpolarizabilities, the isotropic polarizability, polarizability anisotropy invariant and hyperpolarizability are also calculated. The calculated isotropic polarizability of 4-methoxybenzonitrile -73.8781a.u. However, the calculated isotropic polarizability of JK16, JK17, dye 1, dye 2, D5, DST and DSS is 759.9, 1015.5, 694.7, 785.7, 510.6, 611.2 and 802.9 a.u., respectively [51,52]. 
Table 2. Polarizability ( $\alpha$ ) of the dye 4-methoxybenzonitrile (in a.u.).

\begin{tabular}{llllllll}
\hline$\alpha_{\mathrm{xx}}$ & $\alpha_{\mathrm{xy}}$ & $\alpha_{\mathrm{yy}}$ & $\alpha_{\mathrm{xz}}$ & $\alpha_{\mathrm{yz}}$ & $\alpha_{\mathrm{zz}}$ & $\alpha$ & $\Delta \alpha$ \\
\hline-84.7170 & 11.7033 & -66.9151 & 0.1521 & 0.0701 & -70.0021 & -73.8781 & 16.4767 \\
\hline
\end{tabular}

Table 3. Hyperpolarizability ( $\beta$ ) of the dye 4-methoxybenzonitrile (in a.u.).

\begin{tabular}{lllllllllll}
\hline$\beta_{\mathrm{xxx}}$ & $\beta_{\mathrm{xxy}}$ & $\beta_{\mathrm{xyy}}$ & $\beta_{\mathrm{yyy}}$ & $\beta_{\mathrm{xxz}}$ & $\beta_{\mathrm{xyz}}$ & $\beta_{\mathrm{yyz}}$ & $\beta_{\mathrm{xzz}}$ & $\beta_{\mathrm{yzz}}$ & $\beta_{\mathrm{zzz}}$ & $\beta_{\mathrm{ii}}$ \\
\hline & & & & & & & & & & \\
& & & & & & & & & & \\
43.8543 & 62.8694 & -7.2382 & 44.3447 & 1.4935 & 0.0694 & 0.7438 & -12.6899 & -3.4179 & 0.5890 & 1.69587
\end{tabular}

The above data indicate that the donor-conjugate $p$ bridge-acceptor (D-p-A) chain-like dyes have stronger response for external electric field. Whereas, for dye sensitizers D5, DST, DSS, JK16, JK17, dye 1 and dye 2, on the basis of the published photo-to-current conversion efficiencies, the similarity and the difference of geometries, and the calculated isotropic polarizabilities, it is found that the longer the length of the conjugate bridge in similar dyes, the larger the polarizability of the dye molecule, and the lower the photo-to-current conversion efficiency.

This may be due to the fact that the longer conjugate-p-bridge enlarged the delocalization of electrons, thus it enhanced the response of the external field, but the enlarged delocalization may be not favorable to generate charge separated state effectively. So it induces the lower photo-to-current conversion efficiency.

\section{4. Electronic absorption spectra and sensitized mechanism}

In order to understand the electronic transitions of 4-methoxybenzonitrile, TD-DFT calculations on electronic absorption spectra in vacuum and solvent were performed, and the results are shown in Fig. 3. It is observed that, for 4-methoxybenzonitrile, the absorption in the visible region is much weaker than that in the UV region. The calculated results have a red-shift. The results of TD-DFT have an appreciable red-shift, and the degree of red-shift in solvent is more significant than that in vacuum. The discrepancy between vacuum and solvent effects in TD-DFT calculations may result from two aspects. The first aspect is smaller gap of materials which induces smaller excited energies. The other is solvent effects. Measurements of electronic absorptions are usually performed in Solvent, especially polar solvent, could affect the geometry and electronic structure as well as the properties of molecules through the long-range interaction between solute molecule and solvent molecule. For these reasons it is more difficult to make the TD-DFT calculation is consistent with quantitatively. Though the discrepancy exists, the TD-DFT calculations are capable of describing the spectral features of 4-methoxybenzonitrile because of the agreement of line shape and relative strength as compared with the vacuum and solvent. 


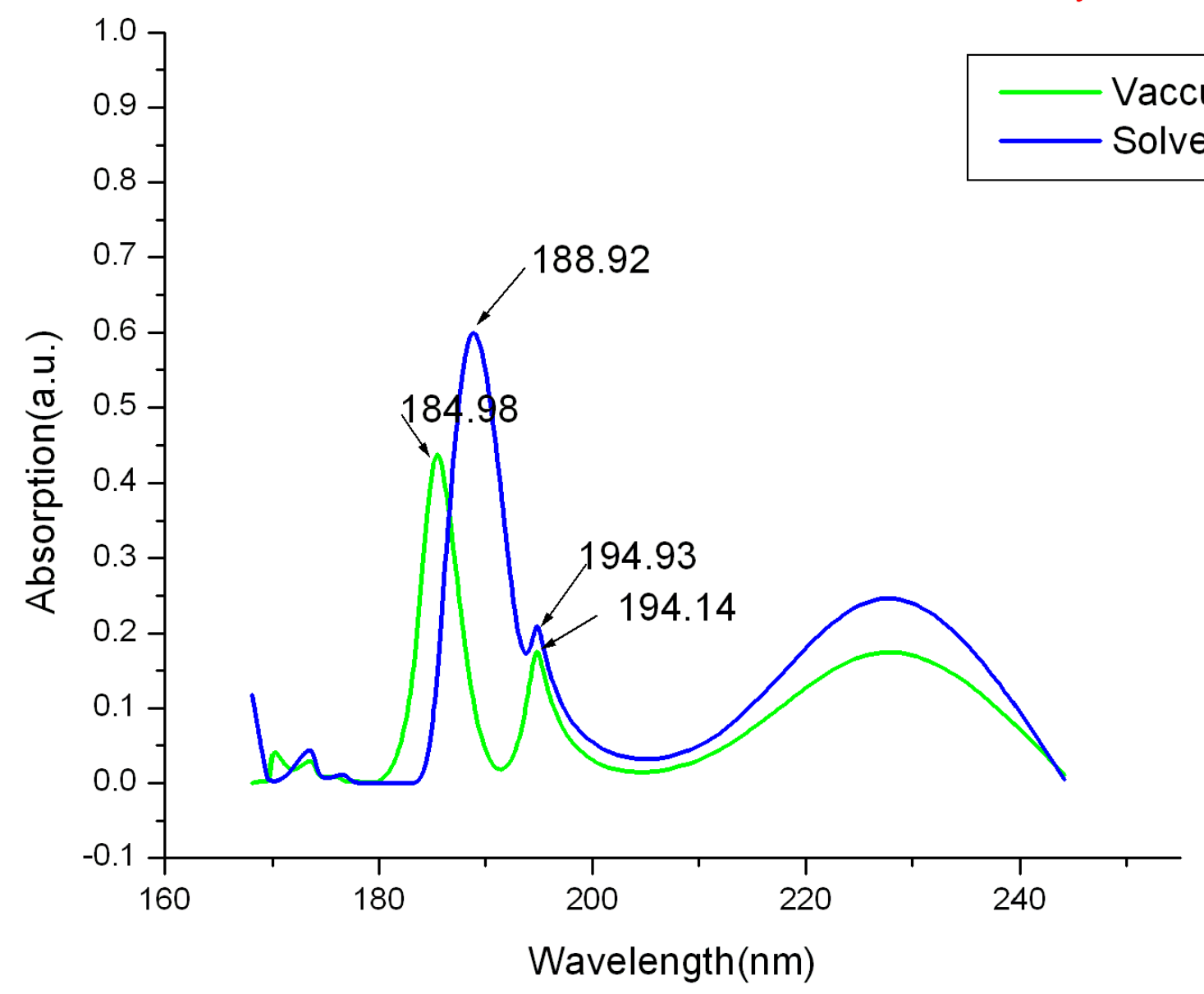

Fig. 3. Calculated electronic absorption spectra of the dye 4-methoxybenzonitrile.

The HOMO-LUMO gap of 4-methoxybenzonitrile in acetonitrile at B3LYP/6-31G $(d, p)$ theory level is smaller than that in vacuum. This fact indicates that the solvent effects stabilize the frontier orbitals of 4-methoxybenzonitrile. So it induces the smaller intensities and red-shift of the absorption as compared with that in vacuum.

In order to obtain the microscopic information about the electronic transitions, the corresponding MO properties are checked. The absorption in visible and near-UV region is the most important region for photo-to-current conversion, so only the 20 lowest singlet/singlet transitions of the absorption band in visible and near-UV region for 4methoxybenzonitrile is listed in Table 4. The data of Table 4 and Fig. 4 are based on the 6$311 \mathrm{G}(\mathrm{d}, \mathrm{p})$ results with solvent effects involved. 
Table 4. Computed excitation energies, electronic transition configurations and oscillator strengths (f) for the optical transitions with $\mathrm{f}>0.01$ of the absorption bands in visible and near- UV region for the dye 4-methoxybenzonitrile in acetonitrile.

\begin{tabular}{|c|c|c|c|}
\hline State & $\begin{array}{c}\text { Configurations composition (corresponding } \\
\text { transition orbitals) }\end{array}$ & $\begin{array}{l}\text { Excitation energy } \\
(\mathrm{eV} / \mathrm{nm})\end{array}$ & oscillator strength (f) \\
\hline 1 & $\begin{array}{c}0.37520(34 \rightarrow 36) 0.20199(35 \rightarrow 36) \\
0.55763(35 \rightarrow 37)\end{array}$ & $5.0776 / 244.18$ & $f=0.0107$ \\
\hline 2 & $\begin{array}{l}-0.11538(34 \rightarrow 36)-0.20973(34 \rightarrow 37) \\
0.58944(35 \rightarrow 36)-0.18426(35 \rightarrow 37)\end{array}$ & $5.4523 / 227.40$ & $f=0.2579$ \\
\hline 3 & $0.69986(35 \rightarrow 38)$ & $5.8325 / 212.57$ & $f=0.0064$ \\
\hline 4 & $0.69592(35 \rightarrow 39)$ & 6.3217 / 196.12 & $f=0.0016$ \\
\hline 5 & $\begin{array}{c}0.11750(29 \rightarrow 37)-0.17833(33 \rightarrow 37) \\
0.49686(34 \rightarrow 36)-0.14880(34 \rightarrow 37) \\
-0.29665(35 \rightarrow 37)\end{array}$ & 6.3637 / 194.83 & $\mathrm{f}=0.2618$ \\
\hline 6 & $0.66178(35 \rightarrow 40) 0.21690(35 \rightarrow 41)$ & $6.4111 / 193.39$ & $f=0.0028$ \\
\hline 7 & $0.68348(34 \rightarrow 38)-0.12824(34 \rightarrow 39)$ & $6.5747 / 188.58$ & $\mathrm{f}=0.0010$ \\
\hline 8 & $\begin{array}{c}-0.10934(29 \rightarrow 36) 0.13654(34 \rightarrow 36) \\
0.55914(34 \rightarrow 37) 0.15150(35 \rightarrow 36) \\
-0.14560(35 \rightarrow 42)\end{array}$ & 6.6950 / 185.19 & $f=0.6552$ \\
\hline 9 & $-0.21825(35 \rightarrow 40) 0.65414(35 \rightarrow 41)$ & $6.7629 / 183.33$ & $\mathrm{f}=0.0000$ \\
\hline 10 & $\begin{array}{c}-0.36935(32 \rightarrow 36) 0.45461(35 \rightarrow 44) \\
0.32959(35 \rightarrow 45)\end{array}$ & 6.9532 / 178.31 & $f=0.0000$ \\
\hline 11 & $0.11026(34 \rightarrow 37) \quad 0.68550(35 \rightarrow 42)$ & $6.9848 / 177.51$ & $\mathrm{f}=0.0045$ \\
\hline 12 & $\begin{array}{c}0.55834(32 \rightarrow 36)-0.11581(32 \rightarrow 37) \\
0.11517(34 \rightarrow 39) 0.32082(35 \rightarrow 44) \\
0.19346(35 \rightarrow 45)\end{array}$ & $7.0141 / 176.76$ & $f=0.0000$ \\
\hline 13 & $\begin{array}{l}0.10330(34 \rightarrow 38) 0.63510(34 \rightarrow 39) \\
0.13941(34 \rightarrow 40)-0.17630(35 \rightarrow 43)\end{array}$ & 7.0457 / 175.97 & $\mathrm{f}=0.0130$ \\
\hline 14 & $0.18908(34 \rightarrow 39) 0.66883(35 \rightarrow 43)$ & $7.1208 / 174.12$ & $\mathrm{f}=0.0015$ \\
\hline 15 & $0.65820(33 \rightarrow 36)$ & 7.1324 / 173.83 & $f=0.0432$ \\
\hline 16 & $\begin{array}{c}-0.10435(34 \rightarrow 390.65048(34 \rightarrow 40) \\
0.17109(34 \rightarrow 41) \\
\end{array}$ & 7.2236 / 171.64 & $f=0.0023$ \\
\hline 17 & $0.65794(33 \rightarrow 37) 0.10807(34 \rightarrow 36)$ & $7.2924 / 170.02$ & $f=0.0605$ \\
\hline 18 & $\begin{aligned} 0.42405(31 \rightarrow 36) & 0.12942(31 \rightarrow 37) \\
0.13675(32 & \rightarrow 36) 0.41383(32 \rightarrow 37) \\
-0.18481(35 & \rightarrow 44) 0.20556(35 \rightarrow 45)\end{aligned}$ & 7.3036 / 169.76 & $\mathrm{f}=0.0010$ \\
\hline 19 & $\begin{array}{l}-0.22748(31 \rightarrow 36)-0.17273(32 \rightarrow 37) \\
-0.36090(35 \rightarrow 44) 0.51038(35 \rightarrow 45)\end{array}$ & 7.3124 / 169.55 & $f=0.0038$ \\
\hline 20 & $\begin{array}{cl}0.47057 & (31 \rightarrow 36)-0.28885(31 \rightarrow 37) \\
& -0.41387(32 \rightarrow 37)\end{array}$ & $7.3731 / 168.16$ & $f=0.0004$ \\
\hline
\end{tabular}


HOMO-3

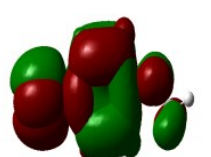

$-9.25(\mathrm{eV})$

HOMO-2

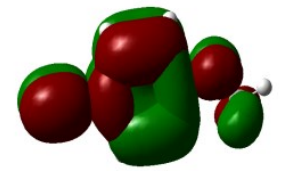

$-9.09(\mathrm{eV})$

HOMO-1

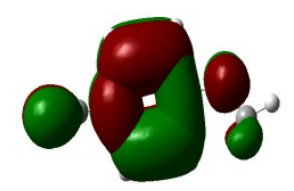

$-7.87(\mathrm{eV})$

HOMO

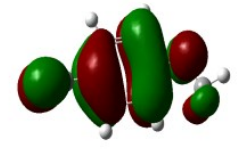

LUMO+3

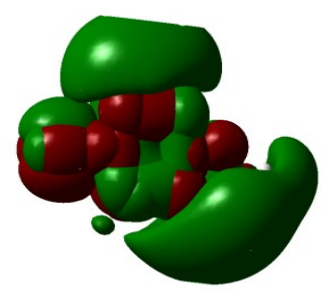

$-0.005(\mathrm{eV})$

$\mathrm{LUMO}+2$

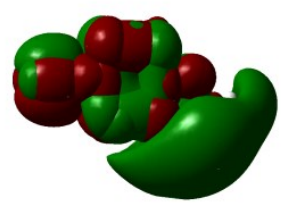

$-0.59(\mathrm{eV})$

LUMO+1

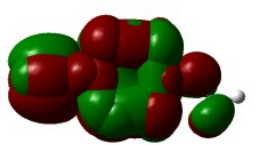

\section{$-1.13(\mathrm{eV})$}

LUMO

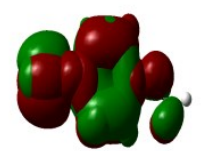

$$
-1.47(\mathrm{eV})
$$

Fig. 4. Isodensity plots (isodensity contour $=0.02$ a.u.) of the frontier orbitals of 4-methoxybenzonitrile.

This indicates that the transitions are photo induced charge transfer processes, thus the excitations generate charge separated states, which should favour the electron injection fromthe excited dye to semiconductor surface.

The solar energy to electricity conversion efficiency $(\eta)$ under AM 1.5 white-light irradiation can be obtained from the following formula:

$$
\eta(\%)=\frac{J_{S C}\left[m A c m^{-2}\right] V_{O C}[V] f f}{I_{0}\left[m W c m^{-2}\right]} \times 100
$$


where $I_{0}$ is the photon flux, $J_{s c}$ is the short-circuit photocurrent density, and $V_{o c}$ is the opencircuit photovoltage, and $f f$ represents the fill factor [53]. At present, the $J_{s c}$, the $V_{o c}$, and the $f f$ are only obtained by experiment, the relationship among these quantities and the electronic structure of dye is still unknown. The analytical relationship between $V_{o c}$ and $E_{L U M O}$ may exist. According to the sensitized mechanism (electron injected from the excited dyes to the semiconductor conduction band) and single electron and single state approximation, there is an energy relationship:

$$
e V_{o c}=E_{L U M O}-E_{C B}
$$

Where, $E_{C B}$ is the energy of the semiconductor's conduction band edge. So the $V_{o c}$ may be obtained applying the following formula:

$$
\mathrm{V}_{\mathrm{oc}}=\frac{\left(\mathrm{E}_{\mathrm{LUMO}}-\mathrm{E}_{\mathrm{CB}}\right)}{\mathrm{e}}
$$

It induces that the higher the $\mathrm{E}_{\mathrm{LUMO}}$, the larger the $V_{o c}$. The results of organic dye sensitizer JK16 and JK17 [39], D-ST and D-SS also proved the tendency [54] (JK16: LUMO $=-2.73 \mathrm{eV}, V_{o c}=0.74 \mathrm{~V}$; JK17: LUMO $=-2.87 \mathrm{eV}, V_{o c}=0.67 \mathrm{~V}$; D-SS: LUMO = $-2.91 \mathrm{eV}, V_{o c}=0.70 \mathrm{~V}$; D-ST: LUMO $\left.=-2.83 \mathrm{eV}, V_{o c}=0.73 \mathrm{~V}\right)$. Certainly, this formula expects further test by experiment and theoretical calculation. The $J_{s c}$ is determined by two processes, one is the rate of electron injection from the excited dyes to the conduction band of semiconductor, and the other is the rate of redox between the excited dyes and electrolyte. Electrolyte effect on the redox processes is very complex, and it is not taken into account in the present calculations. This indicates that most of excited states of 4-methoxybenzonitrile have larger absorption coefficient, and then with shorter lifetime for the excited states, so it results in the higher electron injection rate which leads to the larger $J_{s c}$ of 4methoxybenzonitrile. On the basis of above analysis, it is clear that the 4-methoxybenzonitrile has better performance in DSSC.

\section{CONCLUSIONS}

The geometries, electronic structures, polarizabilities, and hyperpolarizabilities of dye 4-methoxybenzonitrile was studied by using ab initio HF and density functional theory with hybrid functional B3LYP, and the UV-Vis spectra were investigated by using TD-DFT methods. The NBO results suggest that 4-methoxybenzonitrile is a (D-p-A) system. The calculated isotropic polarizability of 4-methoxybenzonitrile is -73.8781 a.u. The calculated polarizability anisotropy invariant of 4-methoxybenzonitrile is 16.4767a.u. The hyperpolarizability of 4-methoxybenzonitrile is 1.69587 a.u.

The electronic absorption spectral features in visible and near-UV region were assigned based on the qualitative agreement to TD-DFT calculations. The absorptions are all ascribed to $\pi \rightarrow \pi^{*}$ transition. The three excited states with the lowest excited energies of 4methoxybenzonitrile is photoinduced electron transfer processes that contributes sensitization of photo-to-current conversion processes. The interfacial electron transfer between semiconductor $\mathrm{TiO}_{2}$ electrode and dye sensitizer 4-methoxybenzonitrile is electron injection process from excited dye as donor to the semiconductor conduction band. Based on the analysis of geometries, electronic structures, and spectrum properties between 4methoxybenzonitrile the role of nitro group is as follows: it enlarged the distance between 
electron donor group and semiconductor surface, and decreased the timescale of the electron injection rate, resulted in giving lower conversion efficiency. This indicates that the choice of the appropriate conjugate bridge in dye sensitizer is very important to improve the performance of DSSC.

\section{ACKNOWLEDGEMENT}

This work was partly financially supported by University Grants Commission, Govt. of India, New Delhi, within the Major Research Project scheme under the approval-cum-sanction No. F.No.34$5 \backslash 2008(\mathrm{SR}) \& 34-1 / \mathrm{TN} / 08$.

\section{References}

[1] B. Li, L. Wang, B. Kang, P. Wang, Y. Qiu, Sol. Energy Mater. Sol. Cells 90 (2006) 549.

[2] B. O’Regan, M. Gratzel, Nature 353 (1991) 737.

[3] M. Gratzel, J. Photochem. Photobiol. C 4 (2003) 145.

[4] M. Gratzel, J. Photochem. Photobiol. A 164 (2004) 3.

[5] M. K. Nazeeruddin, C. Klein, P. Liska, M. Gratzel, Coord. Chem. Rev. 249 (2005) 1460.

[6] T. Dittrich, B. Neumann, H. Tributsch, J. Phys. Chem. C 111 (2007) 2265.

[7] X. Z. Liu, Y. H. Luo, H. Li, Y. Z. Fan, Z. X. Yu, Y. Lin, L. Q. Chen, Q. B. Meng, Chem. Commun. 27 (2007) 2847.

[8] J. B. Xia, F. Y. Li, H. Yang, X. H. Li, C. H. Huang, J. Mater. Sci. 42 (2007) 6412.

[9] M. X. Li, X. B. Zhou, H. Xia, H. X. Zhang, Q. J. Pan, T. Liu, H. G. Fu, C. C. Sun, Inorg. Chem. 47 (2008) 2312.

[10] E. Muller, P. Liska, N. Vlachopoulos, M. Gratzel, J. Am. Chem. Soc. 115 (1993) 6382.

[11] M. K. Nazeeruddin, P. Pechy, T. Renouard, S. M. Zakeeruddin, R. Humphry-Baker, P. Comte, P. Liska, L. Cevey, E. Costa, V. Shklover, L. Spiccia, G. B. Deacon, C. A. Bignozzi, M. Gratzel, J. Am. Chem. Soc. 123 (2001) 1613.

[12] M. Gratzel, Inorg. Chem. 44 (2005) 6841.

[13] K. Hara, T. Sato, R. Katoh, A. Furube, Y. Ohga, A. Shinpo, S. Suga, K. Sayama, H.Sugihara, H. Arakawa, J. Phys. Chem. B 107 (2003) 597.

[14] X. H. Zhang, C. Li, W. B. Wang, X. X. Cheng, X. S. Wang, B. W. Zhang, J. Mater. Chem. 17 (2007) 642 (and reference therein).

[15] M. Liang, W. Xu, F. Cai, P. Chen, B. Peng, J. Chen, Z. Li, J. Phys. Chem. C 111 (2007) 4465 (and reference therein).

[16] W. Xu, B. Peng, J. Chen, M. Liang, F. Cai, J. Phys. Chem. C 112 (2008) 874.

[17] F. De Angelis, S. Fantacci, A. Selloni, Chem. Phys. Lett. 389 (2004) 204.

[18] F. De Angelis, S. Fantacci, A. Selloni, M. K. Nazeeruddin, Chem. Phys. Lett. $415(2005) 115$. 
[19] Y. Xu, W. K. Chen, M. J. Cao, S. H. Liu, J. Q. Li, A. I. Philippopoulos, P. Falaras, Chem. Phys. 330 (2006) 204.

[20] M. K. Nazeeruddin, F. De Angelis, S. Fantacci, A. Selloni, G. Viscardi, P. Liska, S. Ito, B. Takeru, M. Gratzel, J. Am. Chem. Soc. 127 (2005) 16835.

[21] F. De Angelis, S. Fantacci, A. Selloni, M. Gratzel, M. K. Nazeeruddin, Nano. Lett. 10 (2007) 3189.

[22] F. De Angelis, S. Fantacci, A. Selloni, M. K. Nazeeruddin, M. Gratzel, J. Am. Chem. Soc. 129 (2007) 14156.

[23] F. De Angelis, S. Fantacci, A. Selloni, Nanotechnology 19 (2008) 424002.

[24] D. Di Censo, S. Fantacci, F. De Angelis, C. Klein, N. Evans, K. Kalyanasundaram, H. J. Bolink, M. Gratzel, M. K. Nazeeruddin, Inorg. Chem. 47 (2008) 980.

[25] Y. Kurashige, T. Nakajima, S. Kurashige, K. Hirao, Y. Nishikitani, J. Phys. Chem. A $111(2007) 5544$.

[26] M. P. Balanay, D. H. Kim, Phys. Chem. Chem. Phys. 10 (2008) 5121.

[27] P. Persson, M. J. Lundqvist, J. Phys. Chem. B 109 (2005) 11918.

[28] P. Persson, M. J. Lundqvist, R. Ernstorfer, W. A. Goddard III, F. Willig, J. Chem. Theory Comput. 2 (2006) 441.

[29] M. J. Lundqvist, M. Nisling, S. Lunell, B. Akermark, P. Persson, J. Phys. Chem. B 110 (2006) 20513.

[30] M. Nilsing, P. Persson, S. Lunell, L. Ojamae, J. Phys. Chem. C 111 (2007) 12116.

[31] W. R. Duncan, O. V. Prezhdo, Annu. Rev. Phys. Chem. 58 (2007) 143.

[32] W. R. Duncan, O. V. Prezhdo, J. Am. Chem. Soc. 130 (2008) 9756.

[33] L. G. C. Rego, V. S. Batista, J. Am. Chem. Soc. 125 (2003) 7989.

[34] Z. Y. Guo, Y. Zhao, W. Z. Liang, G. H. Chen, J. Phys. Chem. C 112 (2008) 16655.

[35] I. Kondov, M. Clzek, C. Benesch, H. B. Wang, M. Thoss, J. Phys. Chem. C 111 (2007) 11970.

[36] N. Robertson, Angew. Chem. Int. Ed. 45 (2006) 2338.

[37] S. Ito, H. Miura, S. Uchida, M. Takata, K. Sumioka, P. Liska, P. Comte, P. Péchy, M. Grätzel, Chem. Commun. 41 (2008) 5194-5196. 
[38] M. J. Frisch, G. W. Trucks, H. B. Schlegel, G. E. Scuseria, M. A. Robb, J. R. Cheeseman, J. A. Montgomery Jr., T. Vreven, K. N. Kudin, J. C. Burant, J. M. Millam, S. S. Iyengar, J. Tomasi, V. Barone, B. Mennucci, M. Cossi, G. Scalmani, N. Rega, G. A. Petersson, H. Nakatsuji, M. Hada, M. Ehara, K. Toyota, R. Fukuda, J. Hasegawa, M. Ishida, T. Nakajima, Y. Honda, O. Kitao, H. Nakai, M. Klene, X. Li, J. E. Knox, H. P. Hratchian, J. B. Cross, C. Adamo, J. Jaramillo, R. Gomperts, R. E. Stratmann, O. Yazyev, A. J. Austin, R. Cammi, C. Pomelli, J. W. Ochterski, P. Y. Ayala, K. Morokuma, G. A. Voth, P. Salvador, J. J. Dannenberg, V. G. Zakrzewski, S. Dapprich, A. D. Daniels, M. C. Strain, O. Farkas, D. K. Malick, A. D. Rabuck, K. Raghavachari, J. B. Foresman, J. V. Ortiz, Q. Cui, A. G. Baboul, S. Clifford, J. Cioslowski, B. B. Stefanov, G. Liu, A. Liashenko, P. Piskorz, I. Komaromi, R. L. Martin, D. J. Fox, T. Keith, M. A. Al-Laham, C. Y. Peng, A. Nanayakkara, M. Challacombe, P. M. W. Gill, B. Johnson, W. Chen, M. W. Wong, C. Gonzalez, J. A. Pople, Gaussian 03, Gaussian, Inc., Pittsburgh, PA, 2003.

[39] A. D. Becke, J. Chem. Phys. 98 (1993) 5648-5652.

[40] B. Miehlich, A. Savin, H. Stoll, H. Preuss, Chem. Phys. Lett. 157 (1989) 200-206.

[41] C. Lee, W. Yang, R. G. Parr, Phys. Rev. B. 37 (1988) 785-789.

[42] V. Barone, M. Cossi, J. Phys. Chem. A 102 (1998) 1995-2001.

[43] M. Cossi, N. Rega, G. Scalmani, V. Barone, J. Comput. Chem. 24 (2003) 669-681.

[44] M. K. Nazeeruddin, F. De Angelis, S. Fantacci, A. Selloni, G. Viscardi, P. Liska, S. Ito, B. Takeru, M. Gratzel, J. Am. Chem. Soc. 127 (2005) 16835-16847.

[45] M. J. Lundqvist, M. Nilsing, P. Persson, S. Lunell, Int. J. Quantum Chem. 106 (2006) 3214-3234.

[46] D. F. Waston, G. J. Meyer, Annu. Rev. Phys. Chem. 56 (2005) 119-156.

[47] C. R. Zhang, H. S. Chen, G. H. Wang, Chem. Res. Chin. U. 20 (2004) 640-646.

[48] Y. Sun, X. Chen, L. Sun, X. Guo, W. Lu, Chem. Phys. Lett. 381 (2003) 397-403.

[49] O. Christiansen, J. Gauss, J. F. Stanton, Chem. Phys. Lett. 305 (1999) 147-155.

[50] Z. S. Wang, Y. Y. Huang, C. H. Huang, J. Zheng, H. M. Cheng, S. J. Tian, Synth. Met. 14 (2000) 201-207.

[51] C. R. Zhang, Y. Z. Wu, Y. H. Chen, H. S. Chen, Acta Phys. Chim. Sin. 25 (2009) 53-60.

[52] A. Seidl, A. Gorling, P. Vogl, J. A. Majewski, M. Levy, Phys. Rev. B 53 (1996) 3764-3774.

[53] K. Hara, T. Sato, R. Katoh, A. Furube, Y. Ohga, A. Shinpo, S. Suga, K. Sayama, H. Sugihara, H. Arakawa, J. Phys. Chem. B. 107 (2003) 597-606.

[54] C. R. Zhang, Z. J. Liu, Y. H. Chen, H. S. Chen, Y. Z. Wu, L. H. Yuan, J. Mol. Struct. (THEOCHEM) 899 (2009) 86-93. 